\title{
Comprometimento dos stakeholders no turismo: uma análise do desenvolvimento do Geoturismo no município de Gurjão (Paraíba, Brasil)
}

\section{Involvement of stakeholders in Tourism: an analysis of Geotourism development in Gurjão (Paraíba, Brazil)}

\author{
Janaina Luciana de Medeiros (MEDEIROS, J. L. de) ${ }^{*}$, \\ Elayne Gouveia da Silva (SILVA, E. G. da) ${ }^{* *}$, \\ Fernanda Santos Gentil Araújo (ARAÚJO, F. S. G.) ${ }^{* * *}$, \\ Leilianne Michelle Trindade da Silva Barreto (BARRETO, L. M. T. da S.) ${ }^{* * * * *}$
}

\begin{abstract}
RESUMO - Este trabalho tem como objetivo analisar o comprometimento dos stakeholders na atuação do desenvolvimento do geoturismo no município de Gurjão, localizado na região do Cariri Paraibano (Brasil). Para alcançar esse objetivo foi utilizada a abordagem do comprometimento proposta por Medeiros (2003), adaptando à visão da gestão da atividade turística. A pesquisa foi realizada no ano de 2014 e caracteriza-se como exploratória, proporcionando maiores informações sobre o assunto investigado. De acordo com os resultados obtidos, pode-se concluir que os stakeholders do município de Gurjão/PB possuíam o comprometimento com um valor normativo, tornando-se assim, algo a ser considerado na busca das razões dos atores entrevistados se sentirem obrigados a trabalhar com a atividade turística na localidade.
\end{abstract}

Palavras-Chave: Gestão de pessoas; Comprometimento; Stakeholders; Geoturismo; Gurjão/PB.

ABSTRACT - This paper aims to analyze the commitment of stakeholders in the performance of Geotourism development in Gurjão, located in Cariri Region, in Paraíba (Brazil). In order to achieve this aim it was used the commitment approach proposed by Medeiros (2003), adapting to the view of Tourism management. The survey was conducted in 2014 and it is was characterized as exploratory, providing further information on the subject investigated. According to the results, it could be concluded that the stakeholders of Gurjão, Paraíba had the commitment as a normative value, thus,

\footnotetext{
* Formação: Bacharel em Turismo e Mestrado em Turismo pela Universidade Federal do Rio Grande do Norte (UFRN). Endereço físico para correspondência: Rua Vereador Tomaz Pinheiro, 392. Bairro Centro. CEP: 59380000 - Currais Novos/RN - Brasil. E-mail: janainaufrnturismo@ hotmail.com

** Formação: Bacharel em Ecologia pela Universidade Federal da Paraíba (UFPB) e Mestrado em Turismo pela Universidade Federal do Rio Grande do Norte (UFRN). Endereço físico para correspondência: Rua Compositor Agostim Lara, 2060. Bairro: Cristo Redentor. CEP: 58071-431 - João Pessoa/PB - Brasil. E-mail: elaynegouveia@ hotmail.com

*** Formação: Bacharel em Turismo e Mestrado em Turismo pela Universidade Federal do Rio Grande do Norte (UFRN). Endereço físico para correspondência: Rua Ataulfo Alves, 1938, ap. 800, Candelária. CEP: 59.064-570 - Natal/RN - Brasil. E-mail: fernandas_gentil@ hotmail.com

***** Formação: Bacharel em Turismo e Mestrado em Administração pela Universidade Federal do Rio Grande do Norte (UFRN). Doutorado em Administração pela Universidade de São Paulo (USP). Ocupação profissional: Professora Adjunta do Departamento de Turismo da UFRN. Endereço físico para correspondência: Rua dos Pintassilgos, 90, Ap. 1004-A, Pitimbu. CEP: 59.067-300 - Natal/RN - Brasil. E-mail: leiliannebarreto@hotmail.com
} 
that is something to consider in finding the reasons of respondents feeling obliged to work with the tourist activity in the locality.

Key words: People Management; Commitment; Stakeholders; Geotourism; Gurjão/PB. 


\section{INTRODUÇÃO}

Com a globalização surgem novas discussões acerca da valorização das pessoas no seu ambiente de trabalho, que se constituem como fonte de produção de novos conhecimentos, e assim, essenciais para o pleno funcionamento das organizações.

A Gestão de Pessoas compreende a importante função de gerenciar pessoas nas organizações, sejam estas públicas, sejam privadas. As mudanças ocorridas no mundo do trabalho provocaram alterações no modo como as pessoas passaram a ser consideradas no contexto organizacional (FARIAS, 2006).

Assim, a gestão de recursos humanos é um complexo de ações independentes que atua de forma interdependente dentro da organização, sendo, portanto, parte integrante das estratégias empresariais (CARVALHO et al., 2006).

Técnicas de treinamento, inevitavelmente, têm influência sobre a formação do vínculo dos empregados com uma empresa, conforme os efeitos do sentimento de competência pessoal que os novatos apresentam ao desempenhar uma tarefa requisitada. Práticas de recrutamento e seleção apontam as tendências para o sentimento de compromisso, procurando técnicas que identifiquem os candidatos não propensos à assiduidade, ao bom desempenho e à permanência na empresa (CARVALHO et al., 2006).

Dessa forma, os estudos de correlação entre as políticas de recursos humanos e o comprometimento organizacional são recentes e baseiam-se no esforço das organizações no que se refere ao comprometimento de um novato através da socialização e do treinamento. As mensagens transmitidas aos recém-chegados parecem ser mais significativas para determinar e fortalecer o comprometimento (CARVALHO et al., 2006).

Assim, de acordo com Leite, Rodrigues e Albuquerque (2010), na área de comportamento organizacional, os estudos dos vínculos com a organização, especialmente do comprometimento, têm recebido particular atenção, devido ao seu papel de possibilitar um maior entendimento das relações estabelecidas entre os trabalhadores e suas organizações. Do ponto de vista dos atores organizacionais, o comprometimento é esperado por seu impacto em variáveis desejáveis, como desempenho, comportamentos de cidadania organizacional, entre outros. Partindo desse 
pressuposto, muitas pesquisas foram conduzidas nas últimas décadas para avaliar que variáveis contribuem para o desenvolvimento desse vínculo, e que consequências são esperadas com o seu estabelecimento. A consolidação desse campo de estudo destacou o conceito de comprometimento como mais desejável e esperado do que construtos antes predominantes nas pesquisas de comportamento organizacional, a exemplo de motivação e satisfação. Desta forma, tendo o comprometimento o papel de possibilitar um maior entendimento das relações estabelecidas entre os trabalhadores e suas organizações.

Sendo o turismo uma atividade diretamente dependente de pessoas para acontecer, essa crescente valorização do capital humano, aliada à gestão estratégica de pessoas, possui grande importância para o setor. Tanto no âmbito da gestão dos destinos turísticos como em seus empreendimentos, a gestão de pessoas é uma das grandes responsáveis pelo sucesso da atividade, e quando bem trabalhada, gera efeitos positivos sobre o desempenho.

A partir das considerações apresentadas, nesse trabalho se propõe a fazer uma análise do comprometimento não na visão organizacional, mas adaptada a visão da gestão da atividade turística, com o objetivo de identificar o comprometimento dos stakeholders (atores interessados) para a implementação da prática do geoturismo no município de Gurjão/PB, localizado na região do Cariri paraibano, onde foi feito uma relação entre os stakeholders e o segmento do geoturismo no município de Gurjão/PB, adaptando o questionário utilizado por Medeiros (2003), onde é feita a análise através do método de análise de discurso para se alcançar o objetivo proposto.

\section{COMPROMETIMENTO E TURISMO}

Em meio aos estudos sobre comprometimento organizacional, existe a conceitualização na vertente unidimensional e multidimensional, tendo como mais aceitas as propostas por Gouldner (1960) ${ }^{1}$ e por Meyer e Allen (1991) ${ }^{2}$ apud Medeiros,

\footnotetext{
${ }^{1}$ GOULDNER, H. P. Dimensions of organizational commitment. Administrative Science Quaterly, n. 4, p. 468-490, 1960.

${ }^{2}$ MEYER, J. P.; ALLEN, N. J. A three-component conceptualization of organizational commitment. Human Resource Management Review, n. 1, p. 61-89, 1991.
} 
Albuquerque e Marques (2006). Onde o comprometimento é definido como um constructo unidimensional, tendo o seu trabalho o objetivo de identificar os componentes do comprometimento organizacional. Deste modo, o mesmo identifica duas dimensões para o comprometimento, são elas: integração, grau em que o indivíduo é ativo e se sente parte, em vários níveis, de uma organização em particular; e introjecção, grau em que a própria imagem de um indivíduo inclui uma variedade de características e valores organizacionais aprovados. Ressaltando que se sentir parte de uma organização é diferente de introjectar características e valores organizacionais.

$\mathrm{Na}$ vertente unidimensional, o enfoque afetivo dominou os estudos do comprometimento organizacional por um bom tempo. Mowday, Porter e Steers (1982) apud Medeiros; Albuquerque (2005) afirmam que o comprometimento vai além de uma postura de lealdade passiva para com a organização, envolve também um relacionamento ativo que busca o bem-estar desta. Eles ainda argumentam que o comprometimento pode ser caracterizado por no mínimo três fatores: a) uma forte crença e a aceitação dos objetivos e valores da organização; b) estar disposto a exercer um esforço considerável em benefício da organização; c) e um forte desejo de se manter membro da organização.

Após o enfoque afetivo, o mais considerado foi o instrumental, proposto por Becker (1960) $)^{3}$ apud Medeiros; Albuquerque; Marques (2006). Para ele, o comprometimento instrumental é uma tendência do indivíduo em se engajar em linhas consistentes de atividade. O indivíduo permanece na empresa devido aos custos e benefícios associados à sua saída, que seriam trocas laterais, e assim passa a se engajar em linhas consistentes de atividades para se manter no emprego. O enfoque normativo é outro importante a ser considerado, sendo estudado por Wiener (1982), o qual o conceitua como a totalidade das pressões normativas internalizadas para agir num caminho que encontre os objetivos e interesses organizacionais. A visão normativa do comprometimento sugere um foco centrado nos controles normativos por parte das organizações, tais como normas e regulamentos ou ainda como uma missão forte e disseminada dentro da organização.

A vertente multidimensional do comprometimento organizacional começou a ser considerada depois que foi percebido que os enfoques unidimensionais, além de tipos de

\footnotetext{
${ }^{3}$ BECKER, H. S. Notes on the concept of commitment. The American Journal of Sociology, n. 66, p. 32-40, 1960.
} 
comprometimento, eram componentes presentes no vínculo psicológico entre o indivíduo e a organização (MEDEIROS; ALBUQUERQUE, 2005).

Diante disso, Meyer e Allen (1991) conceituam o comprometimento de forma multidimensional, dividindo-o em três componentes: a) comprometimento afetivo, como um apego, um envolvimento, onde ocorre identificação com a organização; b) comprometimento instrumental, percebido como custos associados a deixar a organização; e c) comprometimento normativo, como uma obrigação de permanecer na organização.

$\mathrm{Na}$ vertente multidimensional, Medeiros et al. (2005) apresentam o comprometimento organizacional como um constructo formado por sete dimensões latentes, sendo elas: a) internalização de valores e objetivos organizacionais; b) sentimento de obrigação em permanecer na organização; c) sentimento de obrigação pelo desempenho; d) sentimento de fazer parte; e) sentimento de falta de recompensas e oportunidades; f) linha consistente de atividade; g) escassez de alternativas.

Assim, apresentadas as vertentes do comprometimento organizacional e seus enfoques, Miranda e Zouain (2008) fazem uma relação com a atividade turística, argumentando que os estudos organizacionais, assim como o turismo, acompanham as mudanças sociais, fazendo uso de novos aportes teóricos que possam auxiliar na reflexão teórica da sociedade. Pensadores que tratam o turismo sobre o eixo dos estudos organizacionais e da indústria - como alguns dimensionam, deixam uma explícita ideia da aproximação entre turismo e administração, comprovada na dinâmica das mudanças sociais e organizacionais, evidentes em estudos e pesquisas no cenário acadêmico.

Como exemplo do comprometimento na atividade turística, pode-se apresentar a pesquisa realizada por Medeiros, Albuquerque e Marques (2006), na qual os autores avaliam diversas características organizacionais das empresas hoteleiras, buscando compreender suas relações com o comprometimento dos empregados.

Dessa forma, os resultados obtidos, na pesquisa supracitada, revelam que os hotéis baseados na estratégia de comprometimento, com estrutura organizacional descentralizada, com valorização das pessoas, trabalham em equipe, confiança e um alinhado sistema de recursos humanos, possuem empregados com comprometimento afetivo ou nova concepção, e têm melhor desempenho do que os hotéis baseados na estratégia de controle ou antiga concepção. 
Adaptando o conceito para atividade turística de forma geral, o comprometimento pode ser entendido como o envolvimento dos órgãos e entidades responsáveis com a gestão do turismo, estimulando um esforço considerável em prol da atividade, o qual pode ser afetado pela natureza do vínculo, que pode ser de ordem afetiva, instrumental ou normativa.

Medeiros et al. (2005) afirmam que cada vez mais se têm investido grande esforço na busca e retenção de pessoas melhor qualificadas e que estejam dispostas a se comprometer com os locas. Assim, os procedimentos de recrutamento e seleção de pessoal tentam fornecer mais indivíduos comprometidos e com um alto desempenho. Partindo desse pressuposto, acredita-se que a busca e retenção de pessoas melhor qualificadas e dispostas a se comprometer para assumirem os cargos dos órgãos e entidades responsáveis pela gestão do turismo, favorecem positivamente o sucesso da atividade em uma localidade.

Portanto, o comprometimento no turismo torna-se necessário, pois se espera que os atores se identifiquem com o lugar em que está inserido, para que assim, possa estar realizando uma prática em comum acordo com os objetivos que se pretende alcançar para buscar um melhor posicionamento de um destino turístico no mercado.

No próximo tópico será feita uma relação dos stakeholders (grupos de interesse) com o Geoturismo, segmento da atividade turística.

\section{A RELAÇÃO DOS STAKEHOLDERS E O GEOTURISMO}

Parafraseando Farias e Maracajá (2012) o turismo é uma grande fonte de emprego e renda para uma localidade, envolvendo os mais diversos profissionais, onde se ressalta que o sucesso dessa atividade depende não só das belezas de um lugar, mas, principalmente, de uma prestação de serviços adequada, da qualidade desses serviços e da hospitalidade de todos os envolvidos, e com esse deslocamento de pessoas além de provocar a geração de vários empregos diretos e indiretos, contribui também para ampliar o universo intelectual do turista, a partir do intercâmbio social e cultural que esta atividade pode possibilitar em seus mais diversos segmentos. 
Assim, uma dessas práticas é o geoturismo, que é um segmento da atividade turística que está relacionado com os recursos naturais, incluindo os aspectos geológicos e geomorfológicos, ou seja, os fatores abióticos, e pode ter, fundamentalmente, três motivações, sejam elas a recreação, o lazer e o aprendizado.

O primeiro conceito de geoturismo foi criado por Thomas Hose em 1995, sendo aprimorado em 2000. Esse conceito está relacionado com a promoção dos valores e benefícios de lugares e materiais geológicos e geomorfológicos, assegurando sua conservação, seja para o uso de estudantes, turistas ou demais pessoas com interesse recreativo ou de lazer.

Vale ressaltar que Thomas Hose não foi o único a definir o geoturismo. Muitos outros estudiosos e instituições também buscaram conceituar esse segmento, sendo que alguns priorizaram os aspectos geológicos, outros os geomorfológicos, e uns o relacionaram com o turismo didático. Entre esses estudiosos destacam-se: Nascimento, Ruchkys e Mantesso Neto (2007); Silva (2007); Rocha e Nascimento (2007); Manosso (2007); Araújo (2005) e Moreira (2008).

Para Moreira (2008), o geoturismo é um segmento do turismo praticado em áreas naturais, tendo como principal motivação para a sua prática o interesse nos aspectos geológicos e geomorfológicos de uma região.

Com isso, o geoturismo é entendido como uma aproximação das pessoas que possuem motivação em participar de atividades que envolvam aprendizado, exploração, descoberta e imaginação, tendo na interpretação um meio eficaz para absorver informações da geoconservação e geologia de forma acessível e de forma sustentável (NASCIMENTO; RUCHKYS; MANTESSO NETO, 2007).

Nesse contexto, o geoturismo possui objetivos que não são apenas de contemplação, tendo uma finalidade didática, possibilitando constituir uma nova forma de oferecer instrumentos para a interpretação e compreensão das particularidades dos lugares visitados (SILVA, 2007).

Dessa forma, nesse segmento se dá destaque ao meio abiótico, através da geodiversidade da região visitada, promovendo o desenvolvimento sustentável, de forma a conservar o patrimônio natural, histórico e cultural, incorporando o fascínio pela história do planeta Terra nos visitantes (ROCHA; NASCIMENTO, 2007). 
Percebe-se que a prática do geoturismo vai além da utilização dos aspectos geológicos como um atrativo turístico. Nesse segmento também se busca a geoconservação e a sustentabilidade do local que está sendo visitado, oferecendo uma oportunidade para que a conservação do patrimônio geológico aconteça quando o impacto de seu uso é cuidadosamente gerido, mas também é, em parte, uma consequência de uma bem sucedida conservação desse patrimônio, assegurando a sua preservação para que seja possível aos turistas desfrutar e aprender acerca dele (MANOSSO, 2007; ARAÚJO, 2005).

Ainda segundo Araújo (2005, p. 40) o "geoturismo e a geoconservação têm uma relação ambivalente, uma vez que o geoturismo pode promover a geoconservação e assim promover esse segmento".

Entende-se que a prática do geoturismo necessita da intervenção e união dos diferentes atores que pretendem trabalhar com esse segmento em sua localidade, procurando utilizar os aspectos geológicos em sua promoção, através de uma interpretação ambiental e cultural da área, e assim gerar benefícios para os envolvidos, principalmente a comunidade local.

O geoturismo é uma prática que faz com que muitos turistas que não possuem conhecimentos sobre a geologia percebam seus aspectos como um componente interessante da paisagem. Dessa forma, essa atividade deve ser organizada e planejada pelos atores de uma determinada região, visto que é uma atividade que pode ser uma alternativa para o fortalecimento da economia, gerando divisas através da circulação de visitantes. Logo, é considerada uma atividade com um potencial de impulsionar o desenvolvimento, permitindo transformar os recursos naturais, culturais e históricos de uma região em potencialidades turísticas, acrescentando assim um maior valor a esses recursos.

No entanto, a atividade do geoturismo pode assumir diferentes níveis de importância no desenvolvimento regional, pois nem todas as regiões têm recursos turísticos idênticos, fazendo com que tenha um caráter dominante, ou apenas um caráter complementar.

Partindo desse pressuposto, dependendo do grau de desenvolvimento de uma localidade ou região, o geoturismo estimula a criação de bens e serviços, que 
beneficiam as populações residentes. Assim, esse segmento tem a capacidade de reorganização de localidades inteiras para o acontecimento dessa atividade.

Nesse sentido, destaca-se que os serviços a serem oferecidos correspondem a características que determinam ou representam a marca de um local turisticamente. Por isso a importância de incluir a participação dos stakeholders no projeto geoturístico, uma vez que esse grupo de pessoas está diretamente ligado às respostas de ações ou reações que serão induzidos.

O termo stakeholders é utilizado dentro da administração, criado para diferenciar e definir de forma mais clara os acionistas de um sistema organizacional dos demais membros envolvidos, que se apresentam como uma base forte dentro de uma organização. Assim, podem-se conceituar os stakeholders como o conjunto de todos os atores envolvidos em uma organização, incluindo qualquer grupo ou indivíduo que possa afetar ou é afetado pelos objetivos organizacionais (CAMPOS, 2006).

Os stakeholders também podem ser caracterizados como todos os atores envolvidos nos ambientes interno e externo de uma organização ou atividade, onde é importante destacar e denominar os de maior importância dentro da atividade turística que, além de gestores públicos e privados, secretarias de turismo, colaboradores do ramo de restauração e hospedagem, como também de entretenimento, agentes de viagens e os turistas, há a população local que afirmam sua identidade cultural a fim de transformá-la em elemento de interesse turístico, como as manifestações culturais, artesanato, identidade histórica da localidade, dentre diversas outras (ARAÚJO; POSENATTO; NASCIMENTO; 2010).

Segundo Savage et al. (1991), as empresas devem traçar metas para relações com stakeholders atuais e em potencial como parte de um processo estratégico contínuo de administração. São metas que devem analisar o impacto potencial dos stakeholders nas unidades estratégicas corporativas e de negócios. Existindo o potencial dos stakeholders-chave como foco para ameaçar ou cooperar, os executivos podem evitar a implementação de planos que serão opostos aos dos stakeholders, reconhecendo suas necessidades, modificando planos para envolvê-los, e esquivando-se de problemas associados com a organização subjugados pelos stakeholders.

Ainda neste estudo, os autores constataram que ao focar no potencial dos stakeholders-chave para ameaçar e cooperar, é possível evitar a implementação de 
planos opostos aos planos dos stakeholders, reconhecer suas necessidades emergentes, modificar planos para envolvê-los e desviar problemas associados à organização.

Dessa forma, sabendo-se que os principais objetivos nas pesquisas de stakeholders são identificar quem são os stakeholders de uma organização e determinar quais tipos de influência eles exercem (ROWLEY, 1997), a identificação desses atores, bem como o índice de comprometimento dos mesmos, corresponderá em investimento potencial no conhecimento e previsão da qualidade de serviços que serão gerados e no alcance do sucesso do geoturismo no local.

Portanto, para que os objetivos a que se propõe o geoturismo aconteçam de forma efetiva é preciso que essa atividade, desde o seu planejamento, deva ser concebida com a participação de todos os stakeholders envolvidos direta $\mathrm{e}$ indiretamente com a atividade turística.

Acredita-se, assim, que a junção desse conhecimento na fase de planejamento da atividade geoturística em um município ou região, aliada às demais medidas de gestão, são ações estratégicas que contribuirão com o sucesso do geoturismo, evidenciando aí a importância da pesquisa dos stakeholders em um determinado local.

\section{METODOLOGIA}

Para a realização desta pesquisa foram adotados alguns procedimentos metodológicos. Inicialmente foi realizado o trabalho de obtenção de dados do município de Gurjão (Paraíba/PB, Brasil), de forma a compreender melhor a realidade da pesquisa. O estudo da literatura se baseou sobre os temas: gestão de pessoas, comprometimento organizacional, geoturismo, stakeholders, tornando-se uma fonte indispensável de informações.

Pensou-se no estudo no município de Gurjão/PB devido o interesse dos atores envolvidos com a prática do geoturismo na localidade e participação efetiva nos encontros programados pelos interessados em promover a atividade turística na localidade, como também participação em eventos executados pelas instituições de ensino em realizar pesquisas com a região, devido o potencial da localidade para a prática geoturística. 
O embasamento deste presente artigo deu-se a partir do inventário e mapeamento realizado no município por Silva e Meneses (2011). A inventariação do patrimônio geológico de Gurjão deu-se a partir da identificação de sete locais que apresentavam maior riqueza de informações no contexto ambiental (ou seja, onde a geodiversidade mostrou-se mais expressiva aliada a outros fatores ecológicos) para serem conservadas e, posteriormente, divulgadas através do geoturismo.

Num segundo momento, foi realizado um levantamento de informações junto a representantes que estavam trabalhando com a atividade turística no município de Gurjão/PB. Foram entrevistados os seguintes stakeholders: 1) Elenilda da Conceição, com formação em licenciatura em Geografia pela Universidade Federal de Campina Grande, posteriormente atuando como professora na Escola Municipal de Ensino Fundamental Áurea Correia de Queiroz; 2) Dione Ramos Queiroz, supervisora de educação do município de Gurjão/PB; 3) José Elias Borges Batista, secretário de educação do município de Gurjão/PB; 4) Yago Garcia, formado em gestão de empresas, posteriormente se tornando professor na Escola Municipal de Ensino Fundamental Áurea Correia de Queiroz; 5) Helena Eulampia da Conceição, representante da comunidade do município de Gurjão/PB, conhecedora da história da cidade e de quase todos os locais onde estão localizados os geossítios; e 6) Helder Francisco Gomes da Silva, representante dos comerciantes locais, proprietário de uma loja característica para a venda de utensílios para a vida no campo. Todos os participantes da pesquisa autorizaram a divulgação de seus dados pessoais.

Cabe ressaltar que, apesar dos entrevistados não trabalharem direto com o turismo, que estavam sendo eles que fomentavam, planejavam e articulavam as atividades turísticas do município.

Para coletar os dados primários da pesquisa, foi utilizado o método de aplicação de questionário, com adaptação do modelo utilizado por Medeiros (2003). O questionário foi composto por 30 indicadores, os quais foram mensurados por uma escala Likert de 6 pontos, variando de discordo totalmente a concordo totalmente, a fim de saber qual o nível de sentimento envolvido no comprometimento dos stakeholders do município de Gurjão/PB com a prática do geoturismo.

Para a análise dos dados, foi retirada a média dos quatro tipos de comprometimento do modelo de Medeiros (afetivo, instrumental, normativo e afiliativo) 
para se alcançar o objetivo proposto, que era saber qual o nível de comprometimento com o geoturismo por parte dos stakeholders que estavam integrando a atividade turística do município de Gurjão/PB.

\section{CARACTERIZAÇÃO DE GURJÃO}

O município de Gurjão está localizado na região do Cariri do Estado da Paraíba, em uma das áreas consideradas como mais secas do Brasil, o Semiárido nordestino. Está inserido na unidade geoambiental do Planalto da Borborema, na microrregião do Cariri Oriental paraibano.

Partindo da capital paraibana, João Pessoa, o acesso até Gurjão se dá pela BR230 até o entroncamento da Praça do Meio do Mundo, a partir daí segue-se pela BR-412 até a entrada para a estrada de acesso ao município pela rodovia PB-176. Onde limita-se ao Norte com os municípios de Juazeirinho e Soledade, ao Sul com o município de São João do Cariri, ao Leste com o município de Boa Vista e ao Oeste com os municípios de Santo André e Parari. (IBGE, 2014).

A composição da vegetação em Gurjão, assim como na região do Cariri paraibano, apresenta os diferentes tipos de vegetação do Domínio das Caatingas, sendo esta a Caatinga hiperxerófila, com feições de Caatinga hiperxerófila ou arbórea densa (AB'SABER, 1969).

Até o ano de 2014, o município apresentava uma população de 3.159 habitantes, distribuídas entre 2.128 na área urbana e 1.031 na área rural (IBGE, 2014).

No tocante ao turismo, Gurjão tem dois eventos bem consolidados: a festa de São Sebastião (padroeiro da cidade) e a Expofeira "Bode Na Rua". Entre outros pequenos eventos que atraem visitantes ao local.

A Festa do Padroeiro São Sebastião ocorre durante o mês de janeiro e é realizada com apresentações religiosas e, sobretudo, culturais que revelam a essência do tradicionalismo da vida simples do homem do Cariri, representado pela figura do vaqueiro. 


\section{ANÁLISE DOS RESULTADOS}

Nesta etapa da pesquisa foi realizada a análise, assim como, a discussão dos resultados obtidos por meio de pesquisa de campo, com a observação do município de Gurjão/PB, como também, a aplicação de questionários com os stakeholders que exerciam influência direta e indiretamente sobre a atividade turística na localidade, com o objetivo de esclarecer o nível de comprometimento pessoal com o andamento do projeto para o sucesso do geoturismo no município.

Diante das informações adquiridas na aplicação dos questionários com os stakeholders de Gurjão/PB foi elaborado o quadro 1 a seguir contendo as médias das devidas respostas dos gestores, onde o instrumento se caracterizou da seguinte forma: (1) - Discordo totalmente; (2) - Discordo muito; (3) - Discordo pouco; (4) - Concordo pouco; (5) - Concordo muito; (6) - Concordo totalmente.

\begin{tabular}{|c|c|c|}
\hline DIMENSÕES & INDICADORES & MÉDIA \\
\hline \multirow{6}{*}{ Afetivo } & Eu me identifico com a filosofia deste segmento. & 5 \\
\hline & Eu concordo com as praticas adotadas pelo meu município. & 5,33 \\
\hline & Eu acredito nos valores e objetivos para a prática do geoturismo. & 6 \\
\hline & $\begin{array}{l}\text { Eu sempre me esforço demasiadamente para que minha localidade atinja os } \\
\text { objetivos. }\end{array}$ & 5 \\
\hline & Eu gostaria de trabalhar com esse segmento por muitos anos. & 5,17 \\
\hline & Este município valoriza os bons princípios. & 4,83 \\
\hline \multirow{8}{*}{ Afiliativo } & Neste município, eu sinto que faço parte do grupo. & 5,17 \\
\hline & Eu realmente sinto que nesse município somos uma grande família. & 4,83 \\
\hline & Sinto que sou plenamente integrado neste município. & 4,5 \\
\hline & Se um dia vier a deixar a prática do geoturismo sentirei bastante saudade. & 5 \\
\hline & Fazer parte do grupo é o que me leva a lutar por este segmento. & 4,67 \\
\hline & Tenho uma imensa satisfação de fazer parte deste município. & 5 \\
\hline & Sinto que meus parceiros me consideram como membro desse município. & 5 \\
\hline & Sou reconhecido por todos no município como um membro do grupo. & 5 \\
\hline \multirow{7}{*}{ Instrumental } & $\begin{array}{l}\text { Para me manter no município, procuro fazer sempre o que é esperado de } \\
\text { mim. }\end{array}$ & 5,5 \\
\hline & $\begin{array}{l}\text { Procuro não transgredir as regras aqui, pois assim sempre manterei meu } \\
\text { contato com o grupo. }\end{array}$ & 5,17 \\
\hline & $\begin{array}{l}\text { Importante é fazer sempre o que me foi solicitado, não adianta ficar } \\
\text { querendo mostrar resultados. }\end{array}$ & 5,5 \\
\hline & $\begin{array}{l}\text { Se todos fizessem sempre o necessário não haveria desligamentos do grupo } \\
\text { do município. }\end{array}$ & 5,5 \\
\hline & $\begin{array}{l}\text { Não gostaria de deixar a prática do geoturismo, já investi bastante da minha } \\
\text { vida aqui. }\end{array}$ & 5,33 \\
\hline & $\begin{array}{l}\text { Acredito que este município me dá benefícios que dificilmente encontraria } \\
\text { em outro lugar. }\end{array}$ & 5,33 \\
\hline & $\begin{array}{l}\text { A prática do geoturismo me dá muitos benefícios que compensam trabalhar } \\
\text { com esse segmento. }\end{array}$ & 4,67 \\
\hline
\end{tabular}


Continuação...

\begin{tabular}{|l|l|c|}
\hline \multirow{5}{*}{ Normativo } & Parceiros têm a obrigação de sempre cumprir suas tarefas. & 5,33 \\
\cline { 2 - 3 } & $\begin{array}{l}\text { Uma das coisas mais importantes no meu município é cumprir suas normas e } \\
\text { regulamentos. }\end{array}$ & 5,17 \\
\cline { 2 - 3 } & $\begin{array}{l}\text { O bom desempenho no município é uma decorrência de sempre se respeitar } \\
\text { suas regras. }\end{array}$ & 5,33 \\
\cline { 2 - 3 } & Todo parceiro deve buscar atingir os objetivos do município. & 5,67 \\
\cline { 2 - 3 } & $\begin{array}{l}\text { O bom parceiro deve se esforçar para que o município tenha os melhores } \\
\text { resultados possíveis. }\end{array}$ & 5,67 \\
\cline { 2 - 3 } & Todo parceiro deve dedicar-se de corpo e alma ao seu município. & 5,83 \\
\cline { 2 - 3 } & Eu me sinto culpado se não realizar bem minhas tarefas. & 5,67 \\
\cline { 2 - 3 } & Eu tenho obrigação em desempenhar bem minha função no município. & 5,83 \\
\cline { 2 - 3 } & $\begin{array}{l}\text { Eu me sinto obrigado a fazer as coisas cada vez melhor aqui no meu } \\
\text { município. }\end{array}$ & 5,5 \\
\hline
\end{tabular}

QUADRO 1 - MÉDIAS DAS RESPOSTAS DOS INDICADORES DOS ENTREVISTADOS.

Fonte: Adaptado de Medeiros, C. (2003).

Vale ressaltar que, de acordo com o quadro 1 acima, as variáveis do questionário aplicado a esses atores, do município de Gurjão/PB, que atingiram pontuação máxima foram: "Eu acredito nos valores e objetivos para a prática do geoturismo", que teve média igual a 6 , sendo um indicativo da dimensão afetiva do comprometimento. E em relação ao indicativo que recebeu menor aderência, observaram-se dois: o indicativo "fazer parte do grupo é o que leva a lutar por este segmento", da dimensão afiliativo, e o indicativo "eu acredito nos valores e objetivos para a prática do geoturismo", da dimensão afetiva, onde ambos obtiveram uma média de 4,67.

Através da aplicação do questionário com os principais atores que compõem o trade turístico de Gurjão/PB utilizou-se do modelo de Medeiros (2003) para serem extraídas as médias dos quatro tipos de comprometimento, sendo eles: afetivo, instrumental, normativo, e afiliativo, como segue no quadro 2 abaixo:

\begin{tabular}{|c|c|c|c|c|}
\hline \multirow{3}{*}{ Pesquisados } & \multicolumn{4}{|c|}{ TIPOS DE COMPROMETIMENTO } \\
& Afetivo & Afiliativo & Instrumental & Normativo \\
\cline { 2 - 5 } & 4,67 & 3,75 & 4,43 & 5,33 \\
\hline Elenilda & 6,00 & 5,38 & 5,43 & 5,67 \\
\hline Dione & 4,67 & 3,88 & 4,29 & 4,56 \\
\hline José & 5,83 & 5,63 & 6,00 & 6,00 \\
\hline Helena & 5,50 & 5,75 & 5,86 & 5,78 \\
\hline Yago & 4,67 & 5,00 & 5,71 & 6,00 \\
\hline Helder & 5,22 & 4,89 & 5,29 & 5,55 \\
\hline Média & MÉDIAS DOS TIPOS DE COMPROMETIMENTO DOS & STAKEHOLDERS DE \\
QUADRO 2 - & & \\
GURJÃO/PB. \\
Fonte: Dados da pesquisa, 2013.
\end{tabular}


A partir dos dados no quadro 2 se pode afirmar que o presente trabalho possibilitou identificar que os stakeholders do município de Gurjão possuíam um maior grau de comprometimento normativo, média de 5,55, onde esse tipo de comprometimento se dá por meio de crenças do envolvido a respeito das obrigações e dos deveres morais que deve manter para com a localidade (LOPES; HONORIO, 2012; BASTOS, 1993; SIQUEIRA e GOMIDE JÚNIOR, 2004). Seguido do comprometimento instrumental com média 5,29, que seria, segundo Lopes e Honório (2012, p. 5) “o comprometimento visto como função das recompensas e custos associados com a condição de integrante da organização". Assim, o comprometimento afetivo teve média de 5,22, sendo que, o comprometimento afetivo é caracterizado por alguns autores a partir da identificação do indivíduo com as organizações tendo como parte de sua vida os valores do lugar, quando se tem a sensação de sentimento de gosto e afeição (LOPES; HONÓRIO, 2012). Porém, o comprometimento afiliativo teve um menor grau na média, 4,89, desse modo, Borges e Medeiros (2007) colocam que esse comprometimento se refere a uma denotação de um sentimento de fazer parte de um local.

Percebeu-se assim que os stakeholders do município de Gurjão/PB possuíam um sentimento de obrigação de continuar, pois este sentimento estava relacionado a um alto nível de comprometimento por parte do envolvido na situação, seja organização ou um destino turístico (MEDEIROS; SILVA, 2014).

Sobre a corrente de pesquisa normativa, tem-se que o comprometimento é visto como o conjunto de pressões normativas, internalizadas para que o indivíduo se comporte de acordo com os objetivos e metas da organização. Assim, no enfoque normativo se procura trabalhar o plano organizacional por meio da análise da cultura e do lado individual, por meio dos processos motivacionais. Parte do pressuposto de que o comportamento do indivíduo é conduzido de acordo com o conjunto de normas que ele assume internamente (WIENER, 1982; WIENER e VARDI, 1990; ETZIONI, $1975^{4}$ apud NAVES e COLETA, 2003).

Sendo assim, a pesquisa mostrou que os stakeholders estavam satisfeitos com o que estava sendo imposto para a prática do geoturismo no município de Gurjão/PB,

\footnotetext{
${ }^{4}$ ETZIONE, A. Análise comparativa de organizações complexas: sobre o poder, o engajamento e seus correlatos. Rio de Janeiro: Zahar, 1975.
} 
onde procuravam se adaptarem as regras e regulamentos existentes, permanecendo no destino porque se sentiam obrigados a fazerem parte dele.

Portanto, os atores do município de Gurjão/PB possuíam características evidentes nas dimensões levantadas no questionário, onde novas concepções, e estratégias de gestão influenciavam positivamente no comprometimento desse destino, tendo como finalidade um melhor desempenho da prática do geoturismo.

\section{CONSIDERAÇÕES FINAIS}

O tema comprometimento assumiu grande relevância para a compreensão e prática do geoturismo no município de Gurjão/PB. Tendo em vista a crescente preocupação com o meio no qual se estava inserido, os stakeholders do município demonstraram ter estabelecido canais de comunicação, tomado à iniciativa de trabalhar a atividade de modo integrado, participativo e ordenado, visando promover $\mathrm{o}$ beneficiamento de todos os atores envolvidos.

Espera-se que essa pesquisa sirva de base para auxiliar os gestores do município de Gurjão/PB que pretendam continuar trabalhando com o geoturismo, a fim de conhecer os níveis e tipos de comprometimento organizacional dos atores que se engajam nesse segmento.

Conclui-se que, os stakeholders do município de Gurjão/PB demonstraram possuir um comprometimento com um valor normativo, tornando-se algo em que se deve ter o cuidado para se buscar as razões desses atores estarem sentindo-se obrigados e até mesmo presos em estar trabalhando um segmento, ou melhor, estarem trabalhando com a atividade turística na localidade.

Portanto, se percebeu a necessidade de se realizar pesquisas de cunho quantitativo sobre o termo comprometimento direcionado a destinos turísticos na busca de se entender e identificar qual o tipo de comprometimento dos atores envolvidos com a prática turística na gestão desses destinos. E com isso, procurar a instrumentação de métodos adequados para trabalhar com os tipos de comprometimento que possam ser identificados nos resultados desses estudos. 
Enfim, ressalta-se como limitação desse estudo, a sua realização feita com um número pequeno de autores envolvidos com a atividade turística, propondo-se então, estudos mais abrangentes com um maior envolvimento dos stakeholders que compõem uma determinada localidade para que se possa haver uma verificação mais acentuada do comprometimento em destinos, e assim, se possam haver estudos comparativos para um melhor planejamento do turismo.

\section{REFERÊNCIAS}

AB'SABER, A. N. Participação das superfícies aplainadas nas paisagens do nordeste brasileiro. Geomorfologia, n. 19, p. 1-19, 1969.

ARAÚJO, R. M. de; POSENATtO, A. F. G.; NASCIMENTO, A. C. Cultura e as manifestações artísticas como um atrativo turístico em Natal - RN: Um estudo na percepção dos stakeholders. Natal: HOLOS, ano 26, v. 3, p. 119-135, 2010.

ARAÚJO, E. L. da S. Geoturismo: conceptualização, implementação e exemplo de aplicação ao Vale do Rio Douro no Setor Porto-Pinhão. 2005. 219 f. Dissertação (Mestrado em Ciências do Ambiente) - Escola de Ciências, Universidade do Minho, Minho. 2005.

BASTOS, A. V. B. Comprometimento Organizacional: um balanço dos resultados e desafios que cerca essa tradição de pesquisa. Revista de Administração de Empresas, 1993. p. 52-64.

BORGES, E. F.; MEDEIROS, C. A. F. Comprometimento afetivo e afiliativo: uma abordagem comparativa entre os enfoques no contexto profissional dos contadores atuantes na cidade de Natal/RN. Revista de Contabilidade do Mestrado em Ciências Contábeis, Rio de Janeiro, v. 12, n. 3, set.-dez. 2007.

CAMPOS, T. L. C. Administração de Stakeholders: uma questão ética ou estratégica. In: ENCONTRO DA ASSOCIAÇÃO NACIONAL DOS PROGRAMAS DE PÓSGRADUAÇÃO EM ADMINISTRAÇÃO, 26, 2002, Salvador, Anais..., Rio de Janeiro: ANPAD, set. 2002. p. 1-15.

CARVAlHO, A.; CAMPELO, C.; GUEDES, W.; QUELHAS, O. L. G. A gestão de pessoas como estratégia para o comprometimento organizacional. Estudo de caso: Empresa Brasileira de Correios e Telégrafos - ECT. Revista Pesquisa e Desenvolvimento Engenharia de Produção, n. 5, p. 40-51, jun. 2006.

FARIAS, M. de F. B. de. Gestão de pessoas. Brasília: INEPAD, 2006. Disponível em: <http://pt.scribd.com/doc/12910207/Apostila-Gestao-de-Pessoas-2006>. Acesso em: julho de 2014. 
FARIAS, M. F. de; MARACAJÁ, K. F. B. Projeto de educação ambiental em escolas na cidade de Currais Novos (Rio Grande do Norte, Brasil) como facilitador na relação de educação ambiental e o turismo. Revista Turismo e Sociedade, Curitiba, v. 5, n. 1, p. $104-123$, abril de 2012 .

IBGE. Cidades: infográficos - dados gerais do município. Disponível em http://cod.ibge.gov.br/DQD. Acesso em abr. de 2014.

LEITE, N. R. P. RODRIGUES; A. C. de A.; ALBUQUERQUE, L. G. de. Comprometimento Organizacional e Satisfação no Trabalho: Quais as Possíveis Relações com Antecedentes? XIII SEMINÁRIO EM ADMINISTRAÇÃO. ISSN 21773866. 2010.

LOPES, C. A.; HONORIO, L. C. Comprometimento Organizacional: estudo de caso em uma cooperativa da área de educação na cidade de Belo Horizonte em Minas Gerais. Revista Eletrônica de Administração (on line), v. 11, n. 2, ed. 21, jul - dez. 2012.

MANOSSO, F. C. Geoturismo: uma proposta teórico metodológica a partir de um estudo de caso do município de Apucarana-PR. Caderno Virtual de Turismo, Rio de Janeiro, v. 7, n. 2, 2007.

MEDEIROS, C. A. F. Comprometimento Organizacional: Um estudo de suas relações com características organizacionais e desempenho nas empresas hoteleiras. 2003. 166 f. Tese (Doutorado em Administração de Empresas) - Faculdade de Economia, Administração e Contabilidade, Universidade de São Paulo, São Paulo, 2003.

MEDEIROS, C. A. F.; ALBUQUERQUE, L. G.; MARQUES, G. M. Comprometimento organizacional: um estudo de suas relações com características organizacionais e desempenho nas empresas hoteleiras. In: ENCONTRO DA ASSOCIAÇÃO NACIONAL DE PÓS-GRADUAÇÃO E PESQUISA EM ADMINISTRAÇÃO, 30, 2006, Salvador. Anais... Salvador: ANPAD, 2003.

MEDEIROS, C. A. F.; ALBUQUERQUE, L. G. Comprometimento organizacional: um estudo de suas relações com características organizacionais e desempenho nas empresas hoteleiras. Revista POT, v. 5, n. 2, p. 35-64, dez. 2005.

MEDEIROS, C. A. F.; ALBUQUERQUE, L. G.; MARQUES, G. M.; SIQUEIRA, M. Um estudo exploratório dos múltiplos componentes do comprometimento organizacional. Revista Eletrônica de Administração, v. 11, n. 1, p. 1-16, 2005.

MEDEIROS, T. G.; SILVA, J. R. G. de. Os aspectos do comprometimento organizacional de profissionais terceirizados. Departamento de administração. Disponível em: <http://www.pucrio.br/pibic/relatorio_resumo2007/relatorios/ADM/adm_thiago_goncalves_medeiros.pd f>. Acesso em: agosto/2014. 
MEYER, J. P.; ALLEN, N. J. A three-component conceptualization of organizational commitment. In: Human Resource Management Review, v. 1, n. 1, p. 61-89, 1991.

MIRANDA, A. L.; ZOUAIN, D. M. A Aproximação entre o Estudo do Turismo e a Ciência da Administração a Luz do Modelo Tedqual: Caso São Luís. Turismo - Visão e Ação, v. 10, n. 1, p. 113-132, 2008.

MOREIRA, J. C. Patrimônio geológico em unidades de conservação: atividades interpretativas, educativas e geoturísticas. 2008. Tese (Doutorado em geografia) Universidade Federal de Santa Catarina, Florianópolis, 2008.

NASCIMENTO, M. A. L. do; RUCHKYS, Ú. A.; MANTESSO-NETO, V. Geoturismo: um novo segmento do turismo no Brasil. Global Tourism, São Paulo, v. 3, n. 2, 2007.

NAVES, E.M.R.; COLETA, M.F.D. Cultura e Comprometimento Organizacional em Empresas Hoteleiras. Revista de Administração Contemporânea, 7 (Edição Especial), 205-222, 2003.

SAVAGE, G. T.; NIX, T. W.; WHITEHEAD, C. J.; BLAIR, J. D. Strategies for Assessing and Managing Organizational Stakeholders. Academy of Management Executive, v. 5, n. 2, p. 61-75, 1991.

SIQUEIRA, M. M. M.; GOMIDE JR., S. Vínculos do indivíduo com o trabalho e com a organização. In J. C. Zanelli, J. E. Borges-Andrade, \& A.V.B. Bastos (Orgs.), Psicologia, organizações e trabalho no Brasil, Porto Alegre: Artmed, p. 300-330, 2004.

SILVA, E. G.; MENESES, L.F. Inventário de geossítios como subsídio para o geoturismo no município de Gurjão (PB). Revista Brasileira de Ecoturismo, São Paulo, v.4, n.3, p. 361-382, 2011.

SILVA, F. R. A paisagem do Quadrilátero Ferrífero, MG: Potencial para o uso turístico da sua geologia e geomorfologia. $144 \mathrm{f}$. Dissertação (Mestrado em Geografia) - Departamento de Geografia, Universidade Federal de Minas Gerais, Belo Horizonte, 2007.

WIENER, Y. Commitment in organizations: a normative view. Academy of Management Review, n. 7, p. 418-428, 1982.

Recebido em: 26-11-2013.

Aprovado em: 26-12-2014. 